\title{
Risk factors for developing hypoxic respiratory failure in COPD
}

\author{
This article was published in the following Dove Press journal: \\ International journal of COPD \\ 20 July 2017 \\ Number of times this article has been viewed
}

\author{
Josefin Sundh' \\ Magnus Ekström² \\ 'Department of Respiratory Medicine, \\ School of Medical Sciences, Örebro \\ University, Örebro, ${ }^{2}$ Department \\ of Clinical Sciences, Division of \\ Respiratory Medicine and Allergology, \\ Lund University, Lund, Sweden
}

\begin{abstract}
Background: Hypoxemia is associated with worse outcomes in COPD. The aim of the study was to investigate the prevalence, incidence, and risk factors of hypoxic respiratory failure (HRF) in COPD.
\end{abstract}

Patients and methods: This was a longitudinal analysis of data from the Swedish National Register of COPD. HRF was defined as resting saturation $\leq 88 \%$ or long-term oxygen therapy. Risk factors for developing HRF were analyzed using multiple logistic regression and receiver operating characteristic curve analysis.

Results: A total of 3,061 patients were included; mean forced expiratory volume in 1 second was $1.47 \mathrm{~L}$; mean age was 70 years; and 54\% were females. Median follow-up time was 1.8 years (interquartile range 1.3-2.4 years). HRF was present in 43 (1.4\%) patients at baseline and 74 (2.4\%) patients at follow-up. Among patients without HRF at baseline, 49 (1.6\%) developed HRF during follow-up. The risk was highest for patients in Global initiative for Chronic Obstructive Lung Disease (GOLD) 2017 stage IV or groups C or D at baseline. Developing HRF was independently predicted by lower forced expiratory volume in 1 second and lower COPD Assessment Test score, with a c-statistic of 0.84 (95\% CI, 0.70-0.91). When the multivariable model used the GOLD 2017 variables stages I-IV and the dichotomized variables frequent exacerbations and COPD Assessment Test $\geq 10$; the c-statistic increased slightly to 0.86 (95\% CI, $0.80-0.92 ; P<0.0001$ ).

Conclusion: In patients with COPD, the prevalence and incidence of HRF was low and was predicted well by more severe air flow limitation and worse health status. The risk is highest in patients with GOLD stage IV and GOLD groups C or D.

Keywords: COPD, hypoxic respiratory failure, longitudinal analysis, risk factors, GOLD 2017 assessment tool, hypoxemia, lung function, health status

\section{Introduction}

Hypoxic respiratory failure (HRF) is associated with adverse health outcomes in COPD: impaired exercise tolerance, ${ }^{1}$ pulmonary hypertension, ${ }^{2}$ skeletal muscle dysfunction, ${ }^{3}$ polycythemia, ${ }^{4}$ impaired health-related quality of life, increased risk of hospitalization, ${ }^{5}$ and earlier death. ${ }^{6}$ Long-term oxygen therapy improves the survival time in patients with severe hypoxemia due to COPD.,

Only a few longitudinal studies have investigated the risk factors for development of hypoxemia, reporting low lung function, previous exacerbations, heart failure, pulmonary enlargement on computed tomography, smoking history of $>10$ pack years, and obesity to be associated with development of hypoxemia. ${ }^{9,10}$ In addition, lower total lung capacity, lower functional residual capacity, higher resting heart rate, and lower fat mass index were associated with hypoxemia, although not with changes in arterial tension of oxygen $\left(\mathrm{PaO}_{2}\right)$ over time. ${ }^{11}$ Subsequently, knowledge on the epidemiology and risk factors of developing $\mathrm{HRF}$, especially for patients in clinical practice, is limited.
Department of Respiratory Medicine, School of Medical Sciences, Örebro University, 70182 Örebro, Sweden

Tel +46702349517

Fax +4619186526

Email josefin.sundh@oru.se 
The aim of this study was to estimate the prevalence, change over time, and factors associated with developing HRF in patients with COPD.

\section{Patients and methods Study design and subjects}

This was a longitudinal analysis of patients in the Swedish National Register of COPD. ${ }^{12}$ The register was started in 2009 and is run on behalf of the Swedish Respiratory Society with governmental funding. ${ }^{12}$ Outpatient data are entered at patient visits in both primary care and hospital-based outpatient care, including patient demographics, smoking habits, exacerbations, comorbid conditions, oxygen saturation, and treatment. In the most recent annual report from 2015, the national coverage of all patients with severe and very severe COPD was estimated to be $75 \% .^{13}$ The calculation was based on a recent population-based study of prevalence in different COPD stages in Sweden. ${ }^{14}$

Inclusion criteria were a ratio of forced expiratory volume in 1 second $\left(\mathrm{FEV}_{1}\right)$ to the forced vital capacity $(\mathrm{FVC})<0.7$, age $\geq 35$ years, and having at least two registered visits (baseline and follow-up) separated by at least 1 year during the period from January 1, 2013 to January 8, 2016.

\section{Assessments and definitions}

Data were obtained from the Swedish National Register of COPD on sex, age, smoking habits, spirometric $\mathrm{FEV}_{1}$ and FVC, body mass index (BMI), number of exacerbations and hospitalizations due to exacerbations the recent year, COPD Assessment Test (CAT) score, modified Medical Research Council Score (mMRC) breathlessness score, comorbid heart disease or obstructive sleep apnea syndrome, and pharmacologic treatment. Spirometry values were post-bronchodilator as available, or else pre-bronchodilator values. HRF was defined as oxygen saturation $\leq 88 \%$ or use of long-term oxygen therapy. BMI was categorized as $<22,22.0-29.9$, and $\geq 30$, and $\mathrm{mMRC}$ score as $0-1,2,3$, or 4 . According to the Global initiative for chronic Obstructive Lung Disease (GOLD), the variable frequent exacerbations was defined as having at least two exacerbations or one hospitalized exacerbation in the previous year. ${ }^{15}$ High level of symptoms was defined as CAT score $\geq 10 .{ }^{15}$ Disease severity was categorized according to GOLD 2017 as $\mathrm{FEV}_{1}$ in percentage of the predicted normal ( $\mathrm{FEV}_{1} \%$ pred) stages I-IV, and by the presence of symptoms and frequent exacerbations as groups A-D. ${ }^{15}$ COPD treatment groups included: long-acting muscarinic antagonists (LAMA), long-acting beta-2-agonists (LABA), combined bronchodilators (LAMA + LABA), combined LABA and inhaled corticosteroids (LABA + ICS), triple therapy (LAMA + LABA + ICS), and other maintenance treatments.

\section{Statistical analyses}

Patient characteristics were cross-tabulated by the presence of HRF at baseline. The proportions of HRF at baseline and incidence during follow-up distributed by severity of disease were calculated. Among patients without HRF at baseline, risk factors of having developed HRF at follow-up were analyzed using multivariable logistic regression. Factors to be evaluated in the main model were selected based on subject matter knowledge ${ }^{9-11}$ and included sex, age, BMI, $\mathrm{FEV}_{1}$, number of exacerbations in the previous year, CAT score, heart disease, and obstructive sleep apnea syndrome. The predictive ability of the model was assessed as the area under the receiver operator characteristic curve (AUC). Analyses were also performed with the CAT score variable removed, replaced by, or combined with the mMRC variable, and in a separate model including $\mathrm{FEV}_{1} \%$ pred, exacerbations, and CAT score, these three variables were analyzed as ordinal or dichotomized variables according to GOLD 2017. Finally, the influence of COPD treatment groups, in univariable logistic regression and as further adjustment to the main multivariable model, was investigated. A twosided $P$-value $<0.05$ was considered statistically significant. Statistical analyses were performed using SPSS version 22.0 (IBM Corporation, Armonk, NY, USA).

\section{Ethics}

Patients included in the National Register of COPD are informed using oral information from the caregivers and by pamphlets and announcements at the clinics. Oral informed consents were obtained at inclusion from all patients. The study protocol was approved by the Regional Ethical Review Board of Gothenburg (DNr 393-15). The Regional Ethical Review Board of Gothenburg did not require written informed consent to be obtained from the participants because registration implied consent if not specifically expressed otherwise by the patients and the database used for analyses was anonymous to the authors of the study.

\section{Results}

\section{Patient characteristics}

In total, 3,061 patients were included. Baseline characteristics are shown in Table 1. The mean age of the patients was 70 years; 55\% were females; the mean $\mathrm{FEV}_{1}$ was $1.47 \mathrm{~L}$; mean CAT score was 14; and patients had 0.7 exacerbations during the previous year. The median follow-up time from baseline was 1.8 years (interquartile range 1.3-2.4 years). 
Table I Patient characteristics at baseline

\begin{tabular}{|c|c|c|c|}
\hline $\begin{array}{l}\text { Patient } \\
\text { characteristics }\end{array}$ & $\begin{array}{l}\text { All } \\
\text { patients } \\
\text { (n) }\end{array}$ & $\begin{array}{l}\text { Patients } \\
\text { without } \\
\text { hypoxic RF (n) }\end{array}$ & $\begin{array}{l}\text { Patients } \\
\text { with hypoxic } \\
\text { RF (n) } \\
\end{array}$ \\
\hline Females & $\mathrm{I}, 693(55)$ & $\mathrm{I}, 667(55)$ & $26(6 I)$ \\
\hline Age (years) & $70(9)$ & $70(9)$ & $72(8)$ \\
\hline \multicolumn{4}{|l|}{ BMI $\left(\mathrm{kg} / \mathrm{m}^{2}\right)$} \\
\hline$<22$ & $64 \mid(2 I)$ & $635(2 I)$ & $6(14)$ \\
\hline $22.0-29.9$ & I,753 (68) & I,724 (58) & $29(69)$ \\
\hline$\geq 30$ & $609(20)$ & $602(20)$ & $7(17)$ \\
\hline Current smoking & $938(32)$ & $936(32)$ & $2(5)$ \\
\hline Heart disease & $353(12)$ & $343(\mathrm{II})$ & $10(23)$ \\
\hline Sleep apnea syndrome & $57(2)$ & $56(2)$ & $I(2)$ \\
\hline $\mathrm{FEV}_{1}$ & $\mathrm{I} .47(0.60)$ & $\mathrm{I} .48(0.59)$ & $0.93(0.43)$ \\
\hline FEV $\%$ pred & $53(22)$ & $53(22)$ & $37(17)$ \\
\hline \multicolumn{4}{|c|}{ Air flow limitation (GOLD 2017) } \\
\hline I & $185(6)$ & $184(6)$ & I (2) \\
\hline II & $\mathrm{I}, 554(5 \mathrm{I})$ & $\mathrm{I}, 549(52)$ & $5(12)$ \\
\hline III & $\mathrm{I}, 02 \mathrm{I}(34)$ & $1,004(34)$ & $17(42)$ \\
\hline IV & $266(9)$ & $248(8)$ & $18(44)$ \\
\hline $\begin{array}{l}\text { Number of } \\
\text { exacerbations in the } \\
\text { previous year }\end{array}$ & $0.7(1.2)$ & $0.7(1.2)$ & $1.2(1.6)$ \\
\hline CAT score & $14(8)$ & $14(7)$ & $19(8)$ \\
\hline \multicolumn{4}{|l|}{ mMRC score } \\
\hline $0-1$ & I,I60 (49) & $\mathrm{I}, \mathrm{I} 58(50)$ & $2(5)$ \\
\hline 2 & $535(23)$ & $528(23)$ & 7 (19) \\
\hline 3 & $354(15)$ & $344(15)$ & $10(27)$ \\
\hline 4 & $317(13)$ & $299(13)$ & $18(49)$ \\
\hline \multicolumn{4}{|c|}{ Symptoms/exacerbations (GOLD 2017) } \\
\hline A & $491(29)$ & 489 (29) & $2(8)$ \\
\hline B & $877(52)$ & $862(52)$ & $15(58)$ \\
\hline $\mathrm{C}$ & $43(3)$ & $42(3)$ & I (4) \\
\hline$D$ & $279(17)$ & $27 \mid(16)$ & $8(3 I)$ \\
\hline \multicolumn{4}{|l|}{ Treatment } \\
\hline LAMA monotherapy & $426(14)$ & $426(14)$ & $0(0)$ \\
\hline LABA monotherapy & $62(2)$ & $62(2)$ & $0(0)$ \\
\hline LAMA and LABA & $134(4)$ & $132(4)$ & $2(5)$ \\
\hline LABA and ICS & $325(\mathrm{II})$ & $320(\mathrm{II})$ & $5(12)$ \\
\hline LAMA, LABA, and ICS & $\mathrm{I}, \mathrm{I} 33(37)$ & 1,101 (37) & $32(74)$ \\
\hline
\end{tabular}

Note: Data are presented as frequency (column percentages) or mean (standard deviation).

Abbreviations: BMI, body mass index; CAT, COPD assessment test; FEV , forced expiratory volume in I second; $\mathrm{FEV}_{1} \%$ pred, $\mathrm{FEV}, \%$ of predicted value; GOLD, Global initiative for chronic Obstructive Lung Disease; ICS, inhaled corticosteroids; LABA, long-acting beta- 2 agonists; LAMA, long-acting muscarinic antagonists: mMRC, modified Medical Research Council; RF, respiratory failure.

The prevalence of HRF was $1.4 \%$ at baseline, increasing to $2.4 \%$ at follow-up (Figure 1). Patients with HRF had more heart disease, lower lung function, more exacerbations, higher symptom level assessed by CAT or mMRC, and lower prevalence of current smoking. As for pharmacologic treatment, three-fourths of patients with HRF were treated with inhaled triple therapy (Table 1).

\section{Incidence and risk factors of developing HRF}

At follow-up after a median of 1.8 years, $49(1.6 \%)$ of the patients without HRF at baseline had developed HRF.

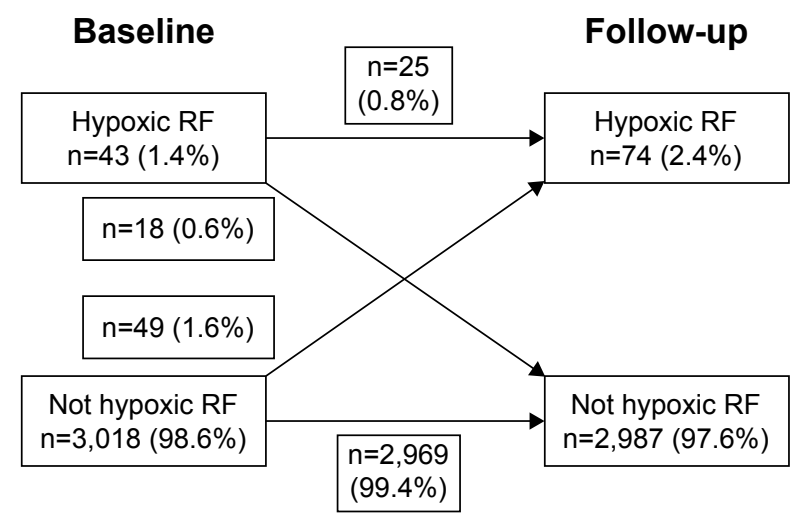

Figure I Hypoxic RF over time.

Notes: Change in hypoxic RF state between baseline and follow-up. Data presented as numbers (percentages).

Abbreviation: RF, respiratory failure.

The incidence of HRF was highest in patients with GOLD 2017 stage IV and of groups $C$ and D (Figure 2). In univariate logistic regression, lower $\mathrm{FEV}_{1}$, higher number of exacerbations in the previous year, more symptoms (higher CAT or mMRC score), presence of BMI $<22$, and obstructive sleep apnea syndrome were associated with increased risk of HRF. In multivariable logistic regression, lower $\mathrm{FEV}_{1}$ and higher CAT score remained independent risk factors for developing HRF (Table 2). The predictive ability of the model was high, with an AUC of 0.84 (95\% CI, 0.70-0.91). Replacing the number of exacerbations with the variable of frequent exacerbations according to GOLD in multivariable logistic regression did not change the findings (data not shown). With removal of CAT score from the multivariable model, development of HRF was still associated with $\mathrm{FEV}_{1}$ (odds ratio [OR] $0.08 ; 95 \% \mathrm{CI}, 0.03-0.20 ; P<0.0001)$ and also with a higher number of exacerbations in the previous year (OR 1.27; 95\% CI, 1.10-1.46; $P=0.001$ ).

Higher mMRC score was associated with development of HRF in univariable analysis (Table 2). However, when adjusting for both CAT and mMRC scores in multivariable analysis, mMRC was no longer a risk factor for HRF (Table 2).

When the GOLD 2017 categorization of CAT score, exacerbations in the previous year, and $\mathrm{FEV}_{1} \%$ pred were used as independent variables, the AUC of the model was 0.84 (95\% CI, 0.78-0.89) and increased slightly to 0.86 (95\% CI, 0.80-0.92), as shown in Figure 3, with further adjustment for the confounders in Table 2.

Maintenance treatment with triple inhaled therapy was statistically significantly associated with developing HRF. None of the treatment alternatives LAMA, LABA, LAMA + $\mathrm{LABA}$ or LABA+ ICS at baseline, or having received physiotherapy, structured education, influenza or pneumococcal vaccinations, were associated with development of HRF. 


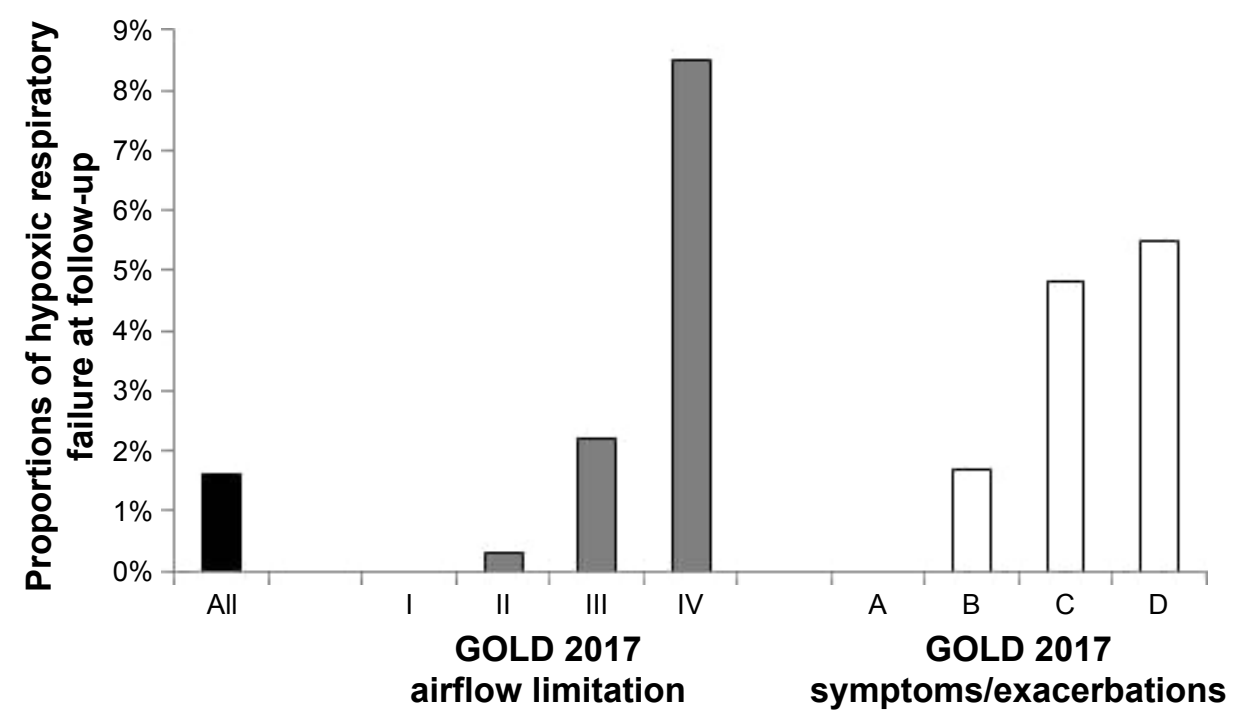

Figure 2 Development of hypoxic respiratory failure by severity of disease at baseline.

Note: Percentages of hypoxic respiratory failure at follow-up, distributed over GOLD stages I-IV and GOLD groups A-D.

Abbreviation: GOLD, Global initiative for chronic Obstructive Lung Disease.

Additional adjustment with inhaled triple therapy to the main multivariable logistic regression models did not substantially change the results (data not shown).

\section{Discussion}

\section{Main findings}

The main findings are that the prevalence and incidence of HRF in patients with predominantly moderate to severe COPD are relatively low, and that the risk of developing HRF is increased in patients with lower lung function and lower health status.

\section{What this study adds}

Only a few studies have reported on the prevalence and incidence of HRF in COPD. In a cross-sectional analysis of the COPDGene cohort, the prevalence of severe resting hypoxemia, defined as saturation $\leq 88 \%$, was as much as $8 \%,{ }^{16}$ while the proportion of patients with HRF in the UPLIFT trial was $2 \% .{ }^{17}$ As the proportion of patients with hypoxemia increases by severity of airflow limitation, our prevalence of $1.4 \%$ at baseline could be consistent with the fact that we have included all COPD stages I-IV. The fact that the incidence of HRF is highest in patients with GOLD

Table 2 Risk factors for incident hypoxic respiratory failure

\begin{tabular}{|c|c|c|c|c|}
\hline & \multicolumn{2}{|c|}{ Univariable logistic regression } & \multicolumn{2}{|c|}{ Multivariable logistic regression } \\
\hline & OR (95\% CI) & $P$-value & OR (95\% CI) & $P$-value \\
\hline Female & $0.92(0.52-1.6 \mathrm{I})$ & 0.76 & $0.53(0.24-1.17)$ & 0.12 \\
\hline Age (per I year) & $1.01(0.98-1.05)$ & 0.42 & $1.02(0.97-1.07)$ & 0.40 \\
\hline $\mathrm{FEV}_{1}($ per I L) & $0.08(0.04-0.17)$ & $<0.0001$ & $0.89(0.03-0.30)$ & $<0.000$ \\
\hline CAT score (per I point) & $1.13(1.08-1.18)$ & $<0.0001$ & $1.07(1.02-1.13)$ & 0.007 \\
\hline \multicolumn{5}{|l|}{ BMI $\left(\mathrm{kg} / \mathrm{m}^{2}\right)$} \\
\hline$<22$ & $0.4 \mathrm{I}(0.2 \mathrm{I}-0.78)$ & 0.007 & $2.25(0.95-5.33)$ & 0.07 \\
\hline $22-29$ & Ref & & Ref & \\
\hline$\geq 30$ & $0.74(0.35-1.56)$ & 0.43 & $1.90(0.7 \mathrm{I}-5.09)$ & 0.20 \\
\hline Heart disease & $0.89(0.35-2.25)$ & 0.80 & $0.48(0.14-1.70)$ & 0.26 \\
\hline Sleep apnea syndrome & $3.59(1.08-11.9)$ & 0.037 & $4.79(0.94-24.3)$ & 0.06 \\
\hline \multicolumn{5}{|l|}{ mMRC* } \\
\hline 2 & $1.65(0.57-4.79)$ & 0.36 & $0.61(0.17-2.21)$ & 0.45 \\
\hline 3 & $2.99(1.08-8.29)$ & 0.036 & $0.47(0.12-1.85)$ & 0.28 \\
\hline 4 & I I.4 (5.03-25.9) & $<0.0001$ & $0.84(0.23-3.04)$ & 0.79 \\
\hline
\end{tabular}

Notes: Results from logistic regression with hypoxic respiratory failure at follow-up as the dependent variable. *The estimates of mMRC are from univariable analysis, and multivariable analysis with all independent variables above and with further adjustment for mMRC.

Abbreviations: BMI, body mass index; CAT, COPD assessment test; FEV , forced expiratory volume in I second; mMRC, modified Medical Research Council; OR, odds ratio; Ref, reference category. 


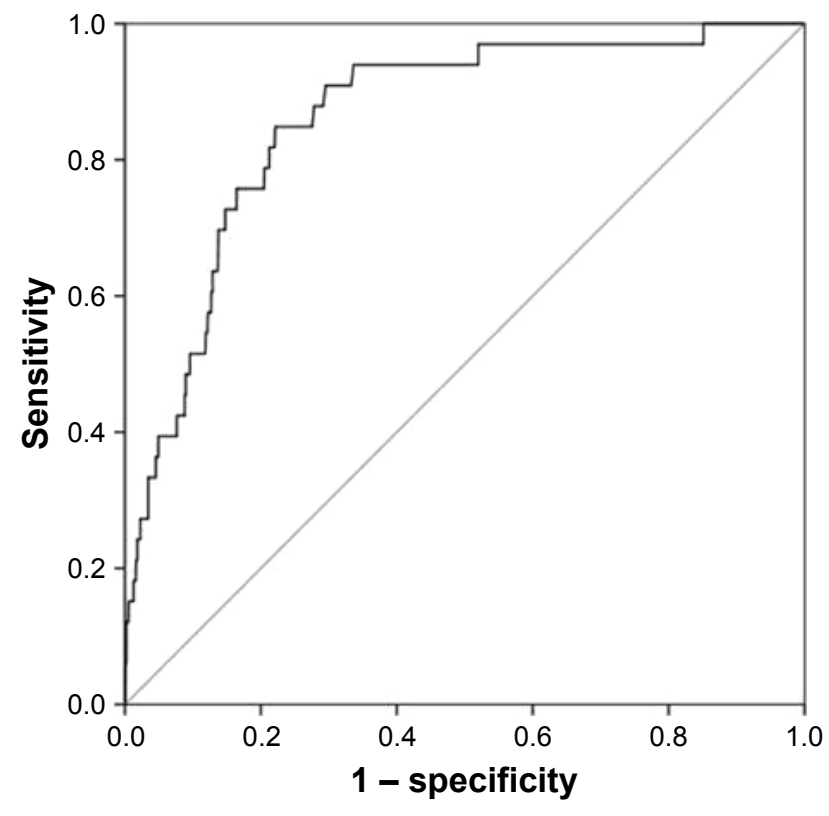

Figure 3 ROC analysis for the main multivariable logistic regression model. Notes: ROC curve for the multivariable logistic regression model including sex, age, body mass index, heart disease, sleep apnea syndrome, and the GOLD 2017 refined assessment tool variables stage I-IV, frequent exacerbations in the previous year, and the dichotomized COPD Assessment Test score. Area under the curve is presented with $95 \% \mathrm{Cl}$.

Abbreviations: GOLD, Global initiative for chronic Obstructive Lung Disease; ROC, receiver operator characteristic.

spirometric stage IV and in patients with low health status and GOLD groups C and D supports the relevance of the recent refined GOLD assessment too ${ }^{15}$ to identify patients at risk for $\mathrm{HRF}$.

The finding that lower lung $\mathrm{FEV}_{1}$ is associated with development of HRF is consistent with a Norwegian longitudinal study. ${ }^{9}$ This study however adds important longitudinal data on the epidemiology and risk factors of HRF in clinical practice, and adds the novel finding that lower health status, assessed using CAT, is independently associated with increased risk of developing HRF in COPD.

Interestingly, exacerbation frequency did not predict the risk of developing HRF when adjusting for confounders, including CAT score. This is in contrast to what was found in the COPDGene study, which, however, did not include health status. ${ }^{10}$ When CAT score was removed from our main model, we also found a statistically significant association of higher number of exacerbations with developing HRF. The incidence of HRF was highest in GOLD stage IV and group $\mathrm{D}$, but was higher in group $\mathrm{C}$ (where all patients have frequent exacerbations) than in group B (where all patients have low health status). We speculate that higher exacerbation frequency and lower health status are both markers for more severe disease, and the effect of exacerbations was captured by reduced health status. Continuous CAT score may also be a more granular and sensitive variable of developing HRF than the total exacerbation frequency in the previous year. Replacing the number of exacerbations with the variable of frequent exacerbations according to GOLD in multivariable logistic regression did not change the finding that lower CAT score, but not exacerbations, predicted development of HRF. However, when the GOLD variables GOLD stage I-IV, frequent exacerbations, and dichotomized CAT score were used in the main model, frequent exacerbations was the most predictive variable. Indeed, this model had strong predictive ability with the highest AUC of 0.86 (95\% CI, 0.80-0.92). The AUC is a measure of goodness of fit for binary outcomes in a logistic regression model. In clinical studies, an AUC of 0.5 means that the model is no better at predicting than chance; values over 0.8 are often interpreted as a strong model and values over 0.9 as an excellent model. An AUC of 1 means that the model perfectly predicts who will experience the outcome and who will not. ${ }^{18,19}$ Thus, all our models had strong predictive ability. The AUC for the model with GOLD stages I-IV, frequent exacerbations and the dichotomized CAT score was 0.84 , and this increased only slightly to 0.86 with further adjustment for other confounders. Thus, the refined 2017 GOLD assessment tool seems very suitable to predict development of HRF.

\section{Strengths and limitations}

The major strengths of our study are the national multicenter longitudinal design with data from clinical practice in both primary and secondary care, and that we included more patients than any previous longitudinal study of HRF in clinical practice. Limitations are that hypoxemia was based on pulse oximetry as data on arterial blood gases were unavailable, and that no detailed data on nocturnal desaturation, effort desaturation, total lung volumes, diffusing capacity, and compliance to interventions were available. In addition, the follow-up was relatively short and varied between 1 and almost 4 years. The wide range in follow-up was explained by the use of first and last registered visits in order to get as long follow-up time as possible.

\section{Implications}

The clinical implication of our results is that monitoring of saturation and arterial blood gases in COPD patients is of major importance, not only in patients with low lung function but also in patients with high frequency of exacerbations or low health status. In clinical practice, the 2017 refined assessment tool with GOLD stages I-IV and GOLD groups A-D appears as a clinically useful tool also for identifying patients with risk of developing secondary HRF. 
In our study, having triple inhaled therapy was a marker for more severe disease and did not influence the development of HRF. Future studies in larger populations are needed to address the question whether different pharmacologic and nonpharmacologic interventions can prevent development of hypoxemia.

\section{Conclusion}

The prevalence and incidence of HRF in COPD is low. More severe airflow limitation and worse health status are associated with a higher risk of developing HRF over time, and the risk is highest in patients with GOLD stage IV and GOLD groups C or D.

\section{Acknowledgments}

We thank the National Register of COPD for supplying data to the study. The study was supported by grants from Region Örebro County.

\section{Disclosure}

The authors report no conflicts of interest in this work.

\section{References}

1. Antonucci R, Berton E, Huertas A, Laveneziana P, Palange P. Exercise physiology in COPD. Monaldi Arch Chest Dis. 2003;59(2):134-139.

2. Chaouat A, Naeije R, Weitzenblum E. Pulmonary hypertension in COPD. Eur Respir J. 2008;32(5):1371-1385.

3. Kim HC, Mofarrahi M, Hussain SN. Skeletal muscle dysfunction in patients with chronic obstructive pulmonary disease. Int J Chron Obstruct Pulmon Dis. 2008;3(4):637-658.

4. Vanier T, Dulfano J, Wu C, Desforges JF. Emphysema, hypoxia and the polycythemic response. N Engl J Med. 1963;269:169-178.

5. Garcia-Aymerich J, Monso E, Marrades RM, et al. Risk factors for hospitalization for a chronic obstructive pulmonary disease exacerbation. EFRAM study. Am J Respir Crit Care Med. 2001;164(6):1002-1007.

6. Anthonisen NR, Wright EC, Hodgkin JE. Prognosis in chronic obstructive pulmonary disease. Am Rev Respir Dis. 1986;133(1):14-20.
7. [No authors listed] Continuous or nocturnal oxygen therapy in hypoxemic chronic obstructive lung disease: a clinical trial. Nocturnal Oxygen Therapy Trial Group. Ann Intern Med. 1980;93(3):391-398.

8. [No authors listed] Long term domiciliary oxygen therapy in chronic hypoxic cor pulmonale complicating chronic bronchitis and emphysema. Report of the Medical Research Council Working Party. Lancet. 1981; 1(8222):681-686.

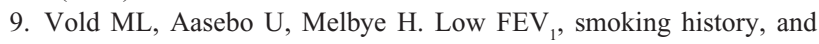
obesity are factors associated with oxygen saturation decrease in an adult population cohort. Int J Chron Obstruct Pulmon Dis. 2014;9(1): 1225-1233.

10. Wells JM, Estepar RS, McDonald MN, et al; COPDGene Investigators. Clinical, physiologic, and radiographic factors contributing to development of hypoxemia in moderate to severe COPD: a cohort study. BMC Pulm Med. 2016;16(1):169.

11. Saure EW, Eagan TM, Jensen RL, et al. Predictors for $\mathrm{PaO} 2$ and hypoxemic respiratory failure in COPD-A three-year follow-up. COPD. 2014;11(5):531-538.

12. Henoch I, Strang S, Lofdahl CG, Ekberg-Jansson A. Health-related quality of life in a nationwide cohort of patients with COPD related to other characteristics. Eur Clin Respir J. 2016;3:31459.

13. Luftvägsregistret, Årsrapport 2015 [Swedish National Register of COPD, Annual report 2015]. Available from: https://registercentrum.blob.core.windows.net/lvr/r/-rsrapport-2015-HJ2YPSmPe.pdf. Accessed July 6, 2017.

14. Backman H, Eriksson B, Ronmark E, et al. Decreased prevalence of moderate to severe COPD over 15 years in northern Sweden. Respir Med. 2016;114:103-110.

15. Global Initiative for Chronic Obstructive Lung Disease. Global strategy for the diagnosis, management, and prevention of chronic obstructive pulmonary disease. Available from: http://www.goldcopd.com. Accessed April 24, 2017.

16. Kim DK, Jacobson FL, Washko GR, et al. Clinical and radiographic correlates of hypoxemia and oxygen therapy in the COPDGene study. Respir Med. 2011;105(8):1211-1221.

17. Tashkin DP, Celli B, Senn S, et al. A 4-year trial of tiotropium in chronic obstructive pulmonary disease. $N$ Engl J Med. 2008;359(15): 1543-1554.

18. Hosmer DW Jr, Lemeshow S, Sturdivant RX. Applied Logistic Regression. 3rd ed. New York, NY: John Wiley \& Sons; 2013.

19. Swets JA. Measuring the accuracy of diagnostic systems. Science. 1988; 240(4857):1285-1293.
International Journal of COPD

\section{Publish your work in this journal}

The International Journal of COPD is an international, peer-reviewed journal of therapeutics and pharmacology focusing on concise rapid reporting of clinical studies and reviews in COPD. Special focus is given to the pathophysiological processes underlying the disease, intervention programs, patient focused education, and self management protocols.

\section{Dovepress}

This journal is indexed on PubMed Central, MedLine and CAS. The manuscript management system is completely online and includes a very quick and fair peer-review system, which is all easy to use. Visit http://www.dovepress.com/testimonials.php to read real quotes from published authors. 